\title{
"FEDERICO GARCÍA LORCA, POETA DRAMÁTICO". SOBRE UN TEXTO INÉDITO DE MANUEL ALTOLAGUIRRE*
}

\author{
"FEDERICO GARCÍA LORCA, A DRAMATIC POET". \\ ABOUT AN UNPUBLISHED TEXT BY MANUEL ALTOLAGUIRRE
}

\author{
Rafael Carrión Arias \\ Universidad de Granada. Granada, España \\ rafacarrion@correo.ugr.es
}

\begin{abstract}
Resumen: Recientemente, se han encontrado en el archivo histórico del Instituto Gorki de Literatura Internacionales de la Academia de Ciencias de Moscú una serie de materiales pertenecientes a autores antifascistas internacionales que la historia había dejado olvidados en la oscuridad del depósito. Entre tales escritos se ha localizado un breve ensayo de Manuel Altolaguirre acerca de la obra dramática lorquiana. Siendo uno de los primeros testimonios escritos de la recepción del poeta granadino, "Federico García Lorca, poeta dramático" de 1937 es un documento inestimable para entender el giro de seriedad que hubo de dar la literatura española en el contexto de emergencia de la Guerra Civil, y los usos que se hicieron de Lorca en dicho contexto.
\end{abstract}

Palabras clave: Manuel Altolaguirre, Federico García Lorca, obra dramática de Lorca, teatro de urgencia, Guerra Civil española, Rusia, URSS, texto inédito.

\begin{abstract}
Recently, several materials written by international antifascist authors fallen into oblivion have been found in the historical archives of the Gorky Literature Institute of International Academy of Sciences in Moscow. Among them there was a short essay written by Manuel Altolaguirre on Lorca's play-writing, which marks one of the first written evidences in the reception of Lorca ever. "Federico García Lorca, a dramatic poet" (1937) is therefore an invaluable document for the understanding of
\end{abstract}

* Este artículo ha sido realizado en el marco del proyecto de investigación "Actualidad de la hermenéutica. Nuevas tendencias y autores FFI2013-41662-P)" financiado por el Ministerio de Ciencia y Tecnología y los Fondos Estructurales de la Unión Europea (FEDER) para el período 2014-2018. 
the serious turn in Spanish literature in the emergency context brought by the Spanish Civil War, and the uses of Lorca's play-writing in this respect.

Keywords: Manuel Altolaguirre, Federico García Lorca, Lorca’s play-writing, emergency theater, Spanish Civil War, Russia, USRR, unpublished text.

Recibido: 13.12.2016. Aceptado: 23.03.2017.

\section{Acerca de "Federico García Lorca, poeta dramático"}

$\mathrm{E}$

L TEXTO QUE AQUí presentamos es un escrito en dos folios mecanografiados y autografiados por el joven editor, impresor y poeta del grupo del 27 Manuel Altolaguirre (Málaga 1905 - Burgos 1959). Lleva por título "Federico García Lorca, poeta dramático”, y ha sido recientemente localizado por el Dr. Maksim Fedorov en el archivo histórico del Instituto Gorki de Literatura Internacionales de la Academia de Ciencias de Moscú ${ }^{1}$. Datado originariamente como del año 1937 por los primeros archivistas del instituto, la realidad es que dentro del escrito no figura ninguna fecha de composición, si bien las menciones de Altolaguirre acerca de la muerte de Lorca ("mártir glorioso de la revolución española") y de la todavía no escenificada Las hijas de Bernarda Alba (finalizada en su composición el 19 de junio de 1936, dos meses antes del asesinato, pero estrenada en 1945 en Buenos Aires con el título de La casa de Bernarda Alba) son dos datos que ayudan a acotar un margen. El hallazgo de este texto se ordena junto a otros descubrimientos recientes, tales como los escritos inéditos de autores de la generación que el director del Archivo España-Rusia 1927-1937, Carlos Flores Pazos, ha encontrado en la biblioteca del hispanista moscovita y padre del teatro de vanguardia soviético Alexandr Viliamovich Fevralski: escritos entre los que se cuentan una obra de teatro inédita de Rafael Alberti (Romance de Don Bueso y de la Infanta cautiva [Flores Pazos, 2006]) y otra del mismo Altolaguirre (Entre dos públicos [Flores Pazos y Torres Nebrera,

${ }^{1}$ Agradezco expresamente a Maksim Fedorov y a Daria Moskovskaja del Instituto Gorki de Literatura Internacionales de la Academia de Ciencias de Moscú por la posibilidad de acceder, trabajar y publicar estos materiales. Una primera publicación en ruso y en castellano del texto original ha aparecido en R. Carrión Arias (2016). 
2005]). En el caso del material que ahora tenemos entre las manos, desconocemos los avatares precisos que lo relegaron al Instituto Gorki (fundado originariamente como universidad vespertina en 1933 por iniciativa del propio Gorki) tanto como las razones que condujeron a los primeros archivistas, cuyo rastro se ha perdido hoy en los registros, a la mencionada datación. Sí sabemos, sin embargo, que es un texto cuyo contenido, salvo la imprescindible dedicación final, fue publicado en su día como parte de un texto mayor titulado "Nuestro teatro", en el que Altolaguirre describía el teatro español contemporáneo (Altolaguirre 1986, 203-211; el texto sobre Lorca ocupa las páginas 209-210). Por ello que lo primero que debemos hacer sea estudiar las razones de esta primera aparición parcial.

\subsection{Hora de España: para un "teatro de urgencia"}

Con Altolaguirre en el consejo de redacción, "Nuestro teatro" apareció en las páginas 29-37 del número 9 (septiembre de 1937) de la revista Hora de España, editada en Valencia acompañando a la nueva sede del gobierno tras el estallido de la Guerra Civil Española. El número previo (agosto de 1937) había recogido la llamada "Ponencia colectiva", elaborada como voz del II Congreso Internacional de Escritores para la Defensa de la Cultura (Valencia-Madrid-París, 4-17 de julio de 1937) y el cual corroboraba las propuestas del Congreso Internacional de Escritores para la Defensa de la Cultura celebrado en París dos años antes. El congreso de París, tal y como el número recordaba, "se reunió para hacer un acto de oposición a la barbarie fascista y también para hacer una exploración, para ejercer una acción en pro de la cultura en la sociedad nueva del comunismo" (Barga, 1937: 6). En el seno de aquel primer congreso, la Alianza de Intelectuales Antifascistas había postulado la creación de un tipo de teatro para el pueblo y a favor de sus intereses de clase, lejos por fin del teatro comercial de comedias ligeras, zarzuelas y sainetes que también imperaba en tiempo de guerra (Doménech Rico, 1999). Como presentaba ahora el II Congreso con términos más filosófico-dialécticos, este nuevo teatro debía aspirar a representar la realidad más allá de sus aparentes formales, es decir significando una esencialidad por la que "no hay ya colisión entre la realidad objetiva y el mundo íntimo"; y esto "[e]n la medida que el pueblo español, por 'la 
fuerza de la sangre', recobra sus valores tradicionales”. Desde el desgarro de la guerra, el teatro debía ser revolucionario, y para ello popular en su búsqueda de lo esencial:

Pues bien; nosotros declaramos que nuestra máxima aspiración es la de expresar fundamentalmente esa realidad, con la que nos sentimos de acuerdo poética, política y filosóficamente. Esa realidad que hoy, por las extraordinarias dimensiones dramáticas con que se inicia, por el total contenido humano que ese dramatismo implica, es la coincidencia absoluta con el sentimiento, con el mundo interior de cada uno de nosotros.

Decimos, y creemos estar seguros de ello, que, por fin, no hay ya colisión entre la realidad objetiva y el mundo íntimo. Lo que no es ni casual ni tampoco resultado sólo de nuestro esfuerzo para lograr esa identificación, sino que significa la culminación objetiva de todo un proceso. En la medida que el pueblo español, por "la fuerza de la sangre", recobra sus valores tradicionales (esto es, aquella parte de su tradición que es un valor, aquella tradición que es positiva), esa integración se produce espontáneamente, como un regalo, cosa que no podía suceder en tanto que no llegase este mismo momento; porque hasta él había tan sólo, por un lado, la lucha, la guerra, pero sin los altos valores que puede tener y que tiene hoy nuestra guerra; y por otro, la sola esperanza (Serrano Plaja, 1937: 89).

Fue en este desafío de la dramaturgia que un equipo formado por autores tales como Rafael Alberti, José Bergamín, Ramón J. Sender o el mismo Manuel Altolaguirre dieron forma a lo que más tarde la mano de Alberti denominaría en 1938 "teatro de urgencia", esto es: un teatro de propaganda y de formación ideológica, sencillo de contenido y de fácil puesta en escena, cuyo objetivo último sería elevar al obrero a las exigencias del momento para derrotar al fascismo y abolir las condiciones de explotación de la sociedad burguesa (Mundi Pedret, 1987: 21). Como se recuerda en una comunicación anónima del 15 de Septiembre de 1938:

Casi todos conocen ya lo que se llama teatro de urgencia. Es un teatro ligero, en el buen sentido de la palabra; un teatro de bolsillo, podíamos decir; pocos personajes - cinco o seis- poca o ninguna tramoya -la imaginación suple; y obras pequeñas, obras relámpago, tan simples y a la 
vez tan precisas, tan eficaces, como un buen cartel moderno o una buena consigna ${ }^{2}$.

O el mismo Manuel Altolaguirre en "Nuestro teatro":

Para la propaganda y distracción en los frentes, el Subcomisariado de Propaganda organizó unas compañías y seleccionó un repertorio. Sería muy fácil clasificar los caracteres que se destacan en la mayoría de estas primeras producciones, casi siempre romances dialogados, farsas entre soldados, campesinos y obreros, contra el moro, el italiano, el alemán y los generales facciosos. Teatro antifascista de gran sencillez de forma y gran unanimidad en su contenido, redactado con la mayor simplicidad, para que pueda ser captado por un público que no entiende de sutilezas literarias (1937).

Eso sí: si la "Ponencia colectiva” de agosto de 1937 recogida en el número 8 de Hora de España surgía para corroborar ese ideario de un arte revolucionario desde la "defensa y la difusión de la cultura" (Machado, 1937: 11-19), también lo hacía, además, para advertir del peligro de convertirse en mero panfleto propagandístico si cometía el error de desatender su calidad artística (Serrano Plaja, 1937: 91). Un arte revolucionario que buscara crear conciencia de clase no sólo no debía renunciar, sino que precisamente debía apelar a ciertas exigencias estéticas a fin de "crear público”. En aquellos días, la referencia para salir airosos en ese proyecto parecía la URSS. Y fue así como, tras el cierre de "Nueva Escena”, en agosto de 1937 nació la compañía "Teatro de Arte y Propaganda" con sede en el Teatro de la Zarzuela (Marrast, 2003: 250). Y también para lo que se envió a Rusia una delegación de escritores -el poeta Miguel Hernández entre ellos- de cara a estudiar las formas, métodos, contenidos y repertorios del teatro soviético.

${ }^{2}$ Anónimo, Un teatro del ejército para el ejército. Publicado en Boletín de Información y Orientación Política (Comisariado General de Guerra, 1er Cuerpo del Ejército), año 1, $\mathrm{N}^{\circ}$ 13, 15 de Septiembre de 1938. Recogido en Marrast, Robert, 1978, Apèndix II. Articles y testimonis, pp. 22-24. 


\section{2. "Federico García Lorca, poeta dramático": de Hora de España a tex- to autónomo}

Si ahora venimos explicitando de manera más o menos circunstanciada este contexto de desarrollo y defensa de un teatro revolucionario, es porque fue desde dicho tejido que en septiembre de 1937, en el número 9 de Hora de España, Altolaguirre publica unos parágrafos sobre el teatro de Lorca integrados en su estudio "Nuestro teatro". Se trataba en efecto de un número bastante reivindicativo en lo político, en el que Antonio Machado dedicaba un escrito a "la Gran República de los Soviets"; o donde se publicaba por primera vez al castellano la célebre carta de Thomas Mann al decano de la facultad de Filosofía como respuesta a la anulación de su doctorado con motivo de la pérdida de la ciudadanía y con la que denunciaba la amenaza nazi en la situación de la Alemania de preguerra; o también donde Bernardo Clariana presentaba una "Crónica general de la guerra civil", Octavio Paz su "Elegía a un joven caído en el frente", o se reseñaba el concierto de música soviética celebrado en el Conservatorio de Valencia en el seno de la Asociación Española de Relaciones Culturales con la URSS (AERCU). En "Nuestro teatro", Altolaguirre hace un recorrido por el teatro reciente, profundizando en su carácter emancipador, y en los rasgos posibles de un "futuro teatro español que se anuncia" (Altolaguirre, 1937: 29) pero que no existe todavía en sus formas definitivas. El teatro, lo mismo que toda la cultura popular, es para Altolaguirre una suerte de fenómeno biológico en continua progresión (Altolaguirre, 1937: 31), tesis que le moverá a distinguir entre "teatro vivo" o teatro presente, y "teatro dormido" o teatro latente. Al teatro dormido lo llama así "porque nunca o casi nunca le vimos levantado del techo", "porque nunca [fue] verdaderamente popular [...]", pero aún así proyecta sus posibilidades sobre un futurible y es por ello un teatro que debemos conservar. Altolaguirre ordena en esta categoría el teatro de Azorín, el de Jacinto Grau, el de los Machado, Gómez de la Serna, Jacinto Méndez, Bergamín, Ugarte, Claudio de la Torre, Casona, e incluso el primer Alberti. Pero, sobre todo, el teatro de Valle Inclán y el de Federico García Lorca, con el agravante de que en el caso de este último fue su prematura muerte de manos del fascismo lo que le impidiera despegar y fertilizar a otros con su toque. Grosso modo "Nuestro teatro" se va centrar en presentar la obra de estos dos autores, especialmente la del fundador de La Barraca. 
El texto objeto del presente estudio ("Federico García Lorca, poeta dramático”) aparece mayormente reproducido en las páginas 35-36 de dicha revista. Sin embargo, es importante subrayar que nuestro texto y el equivalente publicado no son completamente coincidentes. La diferencia fundamental entre el texto dedicado a Lorca en "Nuestro teatro" y el que ahora nosotros salvamos del silencio tiene que ver con la presencia de pasajes contextuales que no aparecen en nuestro texto, los cuales se ven ahora sustituidos por una pequeña dedicatoria final que dirige específicamente el escrito al público soviético en el deseo de que algún día llegue a descubrir la obra del granadino:

Ojalá un día los camaradas de la U.R.S.S. puedan leer y ver representar los maravillosos dramas y comedias de Federico García Lorca, nuestro gran poeta dramático y el mártir más glorioso de la revolución española.

Dada la correspondencia entre la supuesta fecha de redacción y la publicación del número de Hora de España, cabe la incertidumbre de si fue extraído del volumen de la revista o de si, en cambio, fue primero escrito ad hoc para verse luego incluido en el texto mayor publicado. Una duda razonable, habida cuenta de la costumbre que tenía Altolaguirre de reutilizar y recomponer sus materiales, publicados o no, a lo largo de toda su vida literaria (Rozas y Torres Nebrera, 1980: 61), pero que ahora se nos presenta difícil de resolver. En cualquiera de los casos, "Federico García Lorca. Poeta dramático" puede ser considerado perfectamente un texto autónomo en sí mismo, en el que Altolaguirre ofrece una breve descripción de la obra dramática de su amigo y compañero de grupo generacional Federico García Lorca para dedicársela a la Rusia revolucionaria.

De su creciente interés entre 1936 y 1937 por Rusia y su literatura³, y

\footnotetext{
${ }^{3}$ Se ha señalado cómo entre 1936 y 1937 Altolaguirre tuvo cierto contacto con la literatura rusa, bien por medio de sus amigos bien por medio de escritores soviéticos visitantes (Insausti, 2012: 527). Además, habría tenido correspondencia en 1934 con el hispanista ruso F. Kelin, con el que a instancia de Rafael Alberti buscaba abrir una vía para estrenar en Rusia (Flores Pazos/ Torres Nebrera, 2005). El 15 de enero de 1937 había estrenado en el Teatro Español de Madrid Venciste Monátkof de Isaac Steinberg con La Barraca, cuya dirección había asumido tras la muerte de Lorca. Y también editaría y traduciría al castellano junto con O. Savich El convidado de piedra y Festín durante la Peste de Pushkin en el marco de la AERCU en conmemoración del Primer Centenario del Poeta (1837-1937) [Tipografía Catalana de Barcelona, 27 de abril de 1938, 58 páginas, $22 \times 14 \mathrm{~cm}$ ].
} 
avalado en todo caso por dicha dedicatoria final, cabe por tanto relacionar "Federico García Lorca, poeta dramático" con ese contexto general de intercambio cultural con la URSS propio de aquellos días. Pero esto, más allá esta vez de la sencilla promoción de un amigo de generación, o de la denuncia internacional del conflicto bélico recabando apoyos para la defensa. Pues la fuerza de dicha dedicatoria está evidenciando en esta ocasión el fondo de intencionalidad de una exposición cuya búsqueda fundamental, en definitiva, sería la de una contribución radical al debate en torno a las formas de un teatro revolucionario posible, esta vez tomando el teatro de Lorca como modelo. Una referencia con la que Altolaguirre estaría apelando, al mismo tiempo, tanto a los dramaturgos rusos como a sus propios compañeros.

\section{De la naturaleza a lo dramático}

Es en dicho contexto de debate acerca de las formas de un teatro posible que se entiende, entonces, el rasgo más llamativo de "Federico García Lorca, poeta dramático": que se limite meramente a exponer la obra dramatúrgica de Lorca y no el resto de su producción, poética o en prosa. Datado como decimos de 1937, un solo año después del asesinato de Lorca, este pequeño ensayo es pionero y anticipa en algunos aspectos la crítica contemporánea de la obra lorquiana, pues en tanto que editor y amigo personal del poeta, Altolaguirre dispone por aquel entonces de materiales y razones que los estudios sólo conocerían años después. Por otro lado, y como ha quedado establecido más arriba, la específica temática en su contexto de composición invita a encuadrarlo en aquel "teatro de urgencia", revolucionariamente comprometido con la esencia del pueblo español y con la representación de sus posibilidades emancipadoras aunque sin menoscabo de las calidades estéticas. En ese sentido, la verdadera aportación para nosotros del texto que ahora manejamos no sería tanto la profundización en la dramaturgia de Lorca como la utilización que Manuel Altolaguirre hace de ella para las necesidades políticas del momento.

Aunque Lorca había evidenciado su posición política con su firma del manifiesto colectivo del 1 de mayo de 1933 en el Adelanto de la revista 
Octubre "Contra la barbarie fascista que encarcela a los escritores alemanes", no deja de ser menos cierto que su compromiso social, materializado especialmente en su proyecto La Barraca, estaba basado en un didactismo de renovación y lucha contra el oscurantismo, de sustitución del teatro burgués en sus formas, y por tanto con un claro carácter estético más que político-ideológico. ¿̇Incurre aquí entonces Altolaguirre en una instrumentalización de la obra de su amigo? Sí y no. Pues por un lado es innegable que toda historiografía conlleva un cierto grado de manipulación de lo historiado por parte del historiador, y aquí Altolaguirre podría acaso consumir las intenciones vanguardistas a medio plazo de su amigo en su proyecto de emergencia. Sin embargo, de otro lado, no es baladí que sea a Lorca y no a otro a quien Altolaguirre recurra como material de intercambio en la construcción de un teatro verdaderamente revolucionario. Estaríamos en este caso ante un doble juego de instrumentalización, pues Altolaguirre estaría efectivamente sirviéndose de Lorca, pero esto para devolverle su voz robada en un proyecto que la tragedia de su asesinato ahora demostraba como ineludible. Dicho de otra manera, Altolaguirre utilizaría a Lorca precisamente para que la "gran labor literaria, poética" de Lorca influyese sobre todos los demás. Estos serían los términos en los que la exposición, a través de una serie de omisiones y presencias seleccionadas (seis obras representativas más una proyectada), acentuaría en la dramaturgia lorquiana una progresión de lo lírico a lo dramático a través de varias etapas.

Una primera etapa viene representada por su primera obra El maleficio de la mariposa (1920), que Altolaguirre llama "de la naturaleza". Es una obra literaria y lírica, con gran presencia simbólica y mítica marcada sin duda por una primera influencia en Lorca de las corrientes surrealistas. Protagonizado por Curianito, una cucaracha despreciada por el resto debido a su vocación poética pero que encuentra el amor en una mariposa forastera de ala rota, se trata de un teatro que atiende más a "la vía exterior", y lo hace acompañándose de la música y el folclore tradicional, así como de antiguas imágenes de la tradición rural. Altolaguirre no lo menciona, pero la obra sólo tuvo cuatro representaciones y la crítica la consideró un fracaso. Si bien todavía anclada en lo popular, se empiezan a percibir ya en la obra los comienzos de una autoconsideración: 
¿Por qué os causan repugnancia algunos insectos limpios y brillantes que se mueven graciosamente entre las hierbas? ¿Y por qué a vosotros los hombres, llenos de pecados y vicios incurables, os inspiran asco los buenos gusanos que pasean tranquilamente por la pradera tomando el sol en la mañana tibia? ¿Qué motivo tenéis para despreciar lo ínfimo de la Naturaleza? [...] Dile al hombre que sea humilde. iTodo es igual en la Naturaleza! (García Lorca, 2009: 227).

Pero si El maleficio de la mariposa es una obra de contemplación exterior -eso que Altolaguirre denomina "escuchar la voz de la Naturaleza"-, ésta dará paso a una etapa más intimista, en la que el autor "empezó a buscarse a sí mismo". Es la etapa que Altolaguirre denomina del "poeta enamorado", y se inaugura con Mariana Pineda, escrita entre 1923 y 1925 y estrenada dos años después en el Teatro Goya de Barcelona. Se trata de una obra basada en la persona histórica homónima condenada a muerte en 1831 por un delito de rebelión contra la monarquía absoluta de Fernando VII tras haberse encontrado en sus aposentos una bandera/señal de un futuro alzamiento liberal. Tras el triunfo de la revolución liberal española, Mariana Pineda fue convertida en una heroína de la causa, y muchos autores se sumaron a hacerla protagonista de sus obras. En el caso de Lorca, sin embargo, éste no se atiene al mito liberal, sino que la presenta en el marco íntimo de su rebelión personal. Como apunta Altolaguirre con aguda visión, la Mariana Pineda de Lorca "más que un personaje político tiene el carácter de heroína del amor". Visto desde el contexto del "teatro de urgencia”, no deja de ser significativo que Altolaguirre se ocupara de la dirección escénica de esta obra en 1936, para estrenarla en 1937 durante el II Congreso Internacional de Escritores - con Luis Cernuda como Don Pedro.

Si El maleficio de la mariposa incluía las primeras canciones de Lorca, Mariana Pineda mostrará ahora indicios de su cancionero popular ( $A y$, qué fragatita real corsaria, o la relación de los versos alejandrinos del tercer acto con sus odas y elegías), así como de sus primeros romances: $L a$ muerte de Torrijos y La corrida de Ronda. El segundo es el poema que Lorca entregó a José María de Cossío para incluir en su antología de poesía taurina, mientras que el primero está consagrado a la muerte de José María de Torrijos y Uriarte (1791-1831), un militar liberal español fusilado en la playa de Málaga y también tratado por poetas como José de Espronceda, con la diferencia de que ahora Lorca lo presenta igual a Mariana Pineda, i. 
e. de manera intimista. Todos estos elementos refuerzan la idea de que $\mathrm{Ma}$ riana Pineda es una obra más lírica que dramática. Aserción corroborada por el hecho de que, en palabras de Altolaguirre, "casi siempre en todos los personajes se escucha indistintamente la personalísima voz del poeta sin que se marquen las diferencias esenciales a los distintos temperamentos”. De la univocidad propia de la lírica a la plurivocidad propia del drama, Lorca sólo alcanzará este último grado de variedad en su próxima etapa, cuando transforme su escena en un teatro griego.

Esta diferencia entre univocidad y plurivocidad, entre lírica y drama, inauguraría por tanto un tercer período en la producción escénica de Lorca. Es cuando Lorca le confía a Altolaguirre que "yo soy ante todo un poeta dramático”. En La zapatera prodigiosa (1930), por ejemplo, una zapatera casada por conveniencia sueña con amores imposibles, situación que provoca la partida del marido y el conflicto en el pueblo; si bien finalmente, tras el paso del tiempo, el marido vuelve disfrazado de titiritero y el matrimonio se declara abiertamente de nuevo un amor que se celebra con coplas y campanas. Altolaguirre vio en esa obra reminiscencias del teatro barroco de Molière (1622-1673), quien en su juego y musicalidad no respetaba la regla clásica de las tres unidades (de lugar, tiempo y acción) si eso iba en perjuicio del efecto buscado sobre el público. Del mismo modo que vio en Bodas de sangre (1933) una cierta relación con el teatro de Lope de Vega, dramaturgo cuya obra Lorca había dirigido ${ }^{4}$ y cuya influencia se hace notar ya desde su producción como estudiante, especialmente en "el uso estratégico de la canción popular o popularizante” (Lázaro Carreter, 2004: 68) como eje de la acción. Hay en Bodas de sangre, además, varias canciones inspiradas en obras de ese autor, por ejemplo la canción de bodas de Peribañez o El caballero de Olmedo (Soria Olmedo, 2016: 301 y 303; Sánchez, 1950).

Esta comparación entre Lorca y Lope de Vega no es sólo cosa de Altolaguirre, sino que se deja ver igualmente en una antología editada en Valencia ese mismo año por su amigo y compañero poeta Emilio Prados, titulada Homenaje al poeta García Lorca contra su muerte y ofrecida como obse-

${ }^{4}$ Siendo director de La Barraca dirigió Fuenteovejuna y El caballero de Olmedo, La dama boba, y Peribáñez y el Comendador de Ocaña, adaptando los textos y la escenografía a cada contexto. 
quio a los participantes en el II Congreso Internacional de Escritores. Dice ahí Emilio Prados que Lorca "conoce toda España. En gran parte por conocimiento directo, por apoderamiento del sentido íntimo de las formas populares. Y el resto lo inventaba. Lo inventado resulta en él tan popular, tan genuino como lo demás. Lope hacía lo mismo muchas veces: hoy resulta en ocasiones difícil saber qué es lo de Lope y qué lo tomado de la tradición del pueblo" (Prados, 1986: 17). En esa misma publicación, también Dámaso Alonso relacionaba a Lorca con Lope en su común capacidad de expresar "lo español" (Wahnón, 1995: 425-427). Una formulación que refiere a todas luces a aquella esencialidad en los "valores tradicionales" requerida por la "Ponencia colectiva", y que la obra lorquiana no resolverá como una simple imitación de líneas pintorescas, de rasgos fonéticos o dejes del habla, sino como una penetración de sentido en el alma popular española desde la revelación de sus ritos cotidianos y la decodificación de sus relaciones. Por debajo de lo superficial, un estrato de costumbres y tradiciones locales y nacionales constituye la esencia de las generaciones y su memoria. La consideración de este estrato como fuente de verdad es lo que se conoce como neopopularismo, y Lorca lo puso en práctica en las canciones y romances mencionados así como en su respectivo escénico, especialmente a partir de este segundo período.

\section{Federico García Lorca como autor trágico: sencillez y severidad}

Concluye Altolaguirre su escrito sobre el teatro de Lorca profundizando en su culminación trágica. Y pudiera ser por esto que pase por alto, entre otras, obras como la farsa guiñolesca en un acto El retablillo de Don Cristóbal (1930), el "teatro imposible" surrealista de El público (1930), Así que pasen cinco años (1931) o la inacabada La comedia sin título. Efectivamente, Altolaguirre encuentra un especial interés en subrayar los aspectos trágicos en el teatro de Lorca, y para ello menciona Yerma como punto de encuentro entre Lorca y el trágico estoico Séneca; o una tragedia con reminiscencias a Esquilo que Lorca tenía proyectada pero que finalmente no realizó: una obra basada en un hecho real acaecido en la sierra de Granada, que cuenta la historia de un mozo que se enamoró de su jaca y en cuya 
venganza tras su muerte mata con un hacha a su propio padre. Sobre esta obra, Altolaguirre no refiere ningún nombre, pero hoy sabemos que se trata de El hombre y la jaca. Mito andaluz (también conocido como La bestia hermosa), planeada desde 1931 y mencionada por Lorca en una lista redactada entre 1935 y 1936 (Laffranque, en García Lorca et al., 1987: 72-87)5. El caballo como símbolo de la naturaleza, la fuerza y el deseo, cualquier comentarista contemporáneo podrá ver en esa obra tratamientos contenidos sobre una sexualidad prohibida, un asunto latente en la producción de Lorca debido a su hoy conocida homosexualidad (Rivas Cherif, 1957: 1). Es difícil saber si Manuel Altolaguirre no menciona este carácter fundamental de la obra de Lorca porque desconociera la orientación sexual de Lorca o porque simplemente prefirió ignorarla ${ }^{6}$. Si se dio esto último, quizás fuera porque para Altolaguirre la homosexualidad del poeta en nada afectó a su obra, o quizás por las razones públicas de "Federico García Lorca. Poeta dramático", dirigido a una sociedad -la española y la de la URSS- donde ese asunto era todo un anatema. Sea como fuere, Altolaguirre presenta el oscuro argumento de El hombre y la jaca no como un reflejo de (sus) inquietudes personales, sino como muestra de una rica fantasía que trasciende lo personal hasta el corazón de los mitos más incomprensibles de un pueblo. Es decir, como un movimiento de re-acercamiento de lo interno hacia lo externo.

Resulta asimismo interesante la atención especial que Altolaguirre le dedica a este proyecto inacabado de Lorca, además de que lo considere una tragedia cuando, años después, otros amigos de Lorca que también conocían el argumento -Rivas Cherif y a través de él Margarita Xirgú- hablarían de él como si fuera una comedia (Gibson, 1987: 156-157). Probable-

${ }^{5}$ De acuerdo con la costumbre que tenía Lorca de compartir con los amigos su producción en todos sus estadios, este proyecto fue compartido, además de con Altolaguirre, con el director de escena Cipriano de Rivas Cherif, quien en 1940, durante su encarcelamiento en la Dirección de Seguridad de Madrid, compuso un poema de nombre "Romance de la bestia hermosa, sobre un tema inédito de Federico García Lorca"” basado en el argumento lorquiano - pues en palabras de Rivas, y como le había transmitido a Lorca en su momento, la idea le parecía más adecuada para ese formato.

${ }^{6}$ Marcelle Auclair, editora también de Lorca, llegó a reconocer que: "Yo misma y varios de sus numerosos amigos hemos podido frecuentarlo durante años sin sospechar que era homosexual" (Auclair, 1972: 98). Por otro lado, en las entrevistas de Agustín Penón publicadas por Ian Gibson se puede leer: "Se sabía en Granada que era maricón perdido; pero la gente lo aceptaba porque él se imponía con su personalidad” (Gibson, 1990: 152). 
mente le interesara a Altolaguirre subrayar una cierta continuidad en el uso lorquiano de la puesta en escena para fines trágicos. Esto queda acentuado a fuerza de contraste con la presentación acerca de la sobriedad de Las hijas de Bernarda Alba ${ }^{7}$. A diferencia de su producción precedente, esta obra última de Lorca da muestras de una depuración de los excesos míticos y formales a favor de un uso mucho más realista de los elementos, en un proceso que, según Altolaguirre, requirió de Lorca "lucha[r] contra su propio temperamento que le ha llevado siempre a lo más barroco y exuberante de nuestra literatura". Altolaguirre no lo refiere, pero el arranque de la obra, tras la presentación de los personajes, ofrecía en efecto la siguiente aclaración: "El poeta advierte que estos tres actos tienen la intención de un documental fotográfico" (García Lorca, 2005: 138). Esta pretensión de "documental fotográfico" tiende a reducir el uso del verso y de la poesía a favor de un realismo que estiliza el detalle. Y así, citando ahora Altolaguirre explícitamente a Lorca: "He suprimido muchas cosas en esta tragedia, muchas canciones fáciles, muchos romancillos y letrillas. Quiero que mi obra teatral tenga severidad y sencillez".

Esto no hará de ese nuevo estilo, hay que aclararlo, ese "realismo puro" que un prematuro comentario de Adolfo Salazar tras una primera lectura de la obra ("Cada vez que terminaba una escena venía corriendo, inflamado de entusiasmo: iNi una gota de poesía! -exclamaba-. iRealidad! iRealismo puro!" [Salazar, 1938: 30]) hizo recalar como inclinación en gran parte de la crítica (Josephs y Caballero, 2002: 107). La presentación que hace Altolaguirre de Las hijas de Bernarda Alba ayuda, por el contrario, a mantener a distancia esa supuesta aspereza naturalista; y lo hace desde las condiciones de un teatro poético, forjado ahora en el ideal de una nueva economía formal que lo acercará por momentos al "realismo mágico" (Rubia Barcia, 1965). Fue precisamente la mesura en ese nuevo ideal de la simplicidad la que produce, además, ese conjunto de niveles connotativos hoy bien conocidos de la obra, tales como el simbolismo en la nomenclatura de los personajes, el simbolismo escénico, etc... (García-Posada, 1985). A primera

${ }^{7}$ Finalizada su composición el 19 de junio de 1936, dos meses antes del asesinato de Lorca, y escenificada por primera vez en el Teatro Avenida de Buenos Aires en 1945, la versión final la llamó La casa de Bernarda Alba, un título que subrayaba el espacio cerrado en el que tiene lugar la acción. 
vista, el relato de Altolaguirre no parece dar cuenta de estos elementos, lo que en algunos casos se explica por el hecho de que pudieran todavía no estar ahí cuando el malagueño se acercó a la obra (véase p. ej. la importancia de la "casa" como personaje y como espacio ontológico, destacada sólo en la última versión del título). Otros componentes de este teatro poético, sin embargo, sí que figuran en el texto a su manera, como por ejemplo la fantasmagórica tensión sexual de la obra -palpablemente marcada por la ausencia de personajes masculinos- y a la que Altolaguirre alude a la hora de referirla como una tragedia "en la que sólo intervienen mujeres". La sintaxis con la que, en el breve párrafo dedicado a Las hijas de Bernarda Alba, nuestro comentarista articula precisamente esta característica con el ideal clásico de la medida ("severidad y sencillez" dice citando a Lorca), demuestra por la vía de la amplificación que sí era consciente de estos niveles para el último drama del poeta. Y que para él, por tanto, constituían elementos compensatorios que el teatro contemporáneo debiera reconsiderar como escalas ejemplares desde las que empezar a crear.

$$
* * *
$$

Con el énfasis puesto en el modo en el que Lorca alcanzó finalmente la justa medida de la belleza dramática, concluye por tanto Altolaguirre la exposición de la ars dramatica lorquiana de acuerdo a un desarrollo en etapas. Ha sido para el malagueño una progresión en tres momentos (teatro exterior/teatro interior/teatro trágico de contención lírica culminante en Las hijas de Bernarda Alba) que implica una lucha interna ("consiguió esas cualidad luchando contra su temperamento") hasta alcanzar esa forma modélica en rigor y precisión necesariamente aprovechable para la configuración de un teatro de contienda a la vanguardia en la defensa y la construcción revolucionarias. Prácticamente en clave lógico-hegeliana y según el modo tan inconfundiblemente marxista de aquellos años (del ensí al para-sí, y de éste al en-sí/para-sí; o también: de lo múltiple a lo uno, y de ahí a lo uno en lo múltiple), en la cúspide de su producción dramática Lorca daría, según Altolaguirre, con una fórmula estética transmisora de esa tan anhelada síntesis entre realidad objetiva y mundo íntimo a la que -de acuerdo con el II Congreso- el arte debía aspirar.

Si lo aquí planteado por Altolaguirre se corresponde o no con las verdaderas intenciones de Lorca y por qué, es ahí precisamente de donde sa- 
camos rédito de la discusión. Pues, como hemos intentado demostrar a lo largo de este artículo, lejos de sus posibles imperfecciones como crónica historiográfica el valor principal de "Federico García Lorca, poeta dramático" - un texto más entre lo que James Valender ha venido a llamar los "estudios literarios" de Altolaguirre- "estriba en lo que revelan de la estética del propio Altolaguirre, más que en lo que nos enseñan con respecto a la obra de los autores estudiados" (Valender, 1986: 13-14). En mi opinión, este pequeño texto de Altolaguirre, con sus personales acentuaciones y olvidos, dice mucho más de la dramaturgia lorquiana y las condiciones de su primera recepción de lo que a primera vista aparenta. Razón más que suficiente por la que considerarlo un documento inestimable para el estudio del giro de necesidad que tuvo que dar la literatura tras el golpe de Estado y el estallido de la Guerra Civil en España.

\section{Referencias}

Alberti, R. (1938). Teatro de urgencia. Boletín de Orientación Teatral, 1, 5. . (2006). Romance de Don Bueso y de la Infanta Cautiva. En C. Flores Pazos (ed). Romance de don Bueso y de la infanta cautiva: romance antiguo escenificado por Rafael Alberti. Cádiz: Diputación Provincial de Cádiz - Servicio de Publicaciones.

Alonso, D. (1937). Federico García Lorca y la expresión de lo español. En E. Prados (ed.), Homenaje al poeta García Lorca (pp. 11-20). Valencia/Barcelona: Ediciones Españolas, Alonso repetiría la publicación en 1944, 1952 y 1975 (Obras completas. IV. Estudios y ensayos sobre literatura. Tercera parte. Ensayos sobre literatura contemporánea (pp. 758-766). Madrid: Gredos.

Altolaguirre, M. (1937). Nuestro Teatro. Hora de España, 9, 29.37. . (1986). Nuestro Teatro. En J. Valender (ed.), Obras Completas. Vol. 1 (pp. 203-211). Madrid: Istmo. [texto sobre Lorca ocupa páginas 209-210].

Auclair, M. (1972). Vida y muerte de García Lorca. Trans. A. Alberti. México: Era.

Barga, C. (1937). II Congreso Internacional de Escritores. Su significación. Hora de España, 8, 5-10.

Carrión Arias, R. (2016). Мануэль Альтолагирре. Федерико Гарсиа Лорка, драматический поэт. Studia Litterarum, 1 (3-4), 357-364.

Doménech Rico, F. (1999). El teatro en la Guerra Civil española. En ADE Teatro: Revista de la Asociación de Directores de Escena de España, 77, 75-86. Flores Pazos, C. (ed). (2006). Romance de don Bueso y de la infanta cautiva: 
romance antiguo escenificado por Rafael Alberti. Cádiz: Diputación Provincial de Cádiz - Servicio de Publicaciones.

Flores Pazos, C. y Torres Nebrera, G. (2005). Estudios introductorios. En M. Altolaguirre, Entre dos públicos. Málaga: Centro Cultural Generación del 27.

García Lorca, F. (2005). La casa de Bernarda Alba. Edición de M. F. Vilches de Frutos. Madrid: Cátedra. . (2009). El maleficio de la mariposa. Madrid: Cátedra.

García Lorca, F., Staiton, F., Laffranque, L., Fernández, M. y Montesinos, M. (1987). Teatro inconcluso: fragmentos y proyectos inacabados. Granada: Universidad de Granada.

García-Posada, M. (1985). Realidad y transfiguración artística en La casa de Bernarda Alba. En R. Doménech, "La casa de Bernarda Alba" y el teatro de García Lorca (pp. 149-170). Madrid: Cátedra.

Gibson, I. (1987). Federico García Lorca. Volumen II. Barcelona: Grijalbo. . (1990). Agustín Penón: Diario de una búsqueda lorquiana (1955-56). Barcelona: Plaza \& Janés.

Insausti Herrero-Velarde, G. (2012). El teatro de Manuel Altolaguirre: Amor de Madre. Revista de Literatura, 74 (148), 517-540.

Josephs, A. y Caballero, J. (eds.) (2002). Notas a la bibliografía. En F. García Lorca, La casa de Bernarda Alba. Madrid: Cátedra.

Lázaro Carreter, F. (2004). Azaña, Lorca, Valle y otras sombras. Madrid: Alianza.

Machado, A. (1937). Sobre la defensa y la difusión de la cultura. Discurso pronunciado en Valencia en sesión de clausura del Congreso Internacional de Escritores. Hora de España, 8, 11-19.

Marrast, R. (1978). El teatre durant la guerra civil espanyola. Assaig d'historia $y$ documents. Barcelona: Institut del Teatro de Barcelona.

(2003). María Teresa León y el teatro en Madrid durante la guerra civil. En G. Santoja Gómez Agero (coord.), Homenaje a María Teresa León en su centenario (pp. 245-251). Madrid: Sociedad Estatal de Conmemoraciones Culturales.

Mundi Pedret, F. (1987). El teatro de la guerra civil. Barcelona: PPU.

Prados, E. (ed.) (1986 [1937]). Homenaje al poeta Federico García Lorca. Valencia / Barcelona: Ediciones Españolas. Edición facsímil prologada por L. García Montero. Granada: Comisión Nacional del Cincuentenario.

Rivas Cherif, C. (1957). Poesía y drama del gran Federico - La muerte y la pasión de Garcia Lorca. Excelsior, Suplemento dominical, 14335, 27 de enero.

Rozas, J. M. y Torres Nebrera, G. (1980). El grupo poético del 27. Tomo II. Madrid: Cuadernos de Estudio 25.

Rubia Barcia, J. (1965). El realismo "Mágico" de "La casa de Bernarda Alba". Revista Hispánica Moderna, 1/4, 385-398. 
Salazar, A. (1938). "La casa de Bernarda Alba". Carteles, 10 de abril, pp. 30.

Sánchez, Roberto G. (1950). García Lorca. Estudio sobre su teatro. Madrid: Ediciones Jura.

Serrano Plaja, A. (1937). Ponencia colectiva. Hora de España, 8, 81-95.

Soria Olmedo, A. (2016). De Lorca a Lope. En D. Ródenas de Moya (coord.), Anuario Lope de Vega. Texto, literatura, cultura, 22 (pp. 287-309). Universitat Autònoma de Barcelona: Barcelona

Valender, J. (ed.) (1986). Introducción. En M. Altolaguirre, Obras Completas. Vol. 1 (pp. 7-18). Madrid: Istmo.

Wahnón, S. (1995). La recepción de García Lorca en la España de la postguerra. Nueva Revista de Filología Hispánica, XLIII, 2, 409-430. 